\title{
A simple, reproducible, and inexpensive technique in the preparation of explanted emphysematous lungs for ex vivo studies
}

Cliff K. Choong, FRACS, ${ }^{a}$ Fabio J. Haddad, MD, ${ }^{\text {a }}$ Carlo Martinez, BSc, ${ }^{a}$ Ding Z. Hu, MD, ${ }^{a}$ John A. Pierce, MD, ${ }^{b}$ Bryan F. Meyers, MD, ${ }^{a}$ G. Alexander Patterson, MD, and Joel D. Cooper, MD, ${ }^{a}$ St Louis, Mo

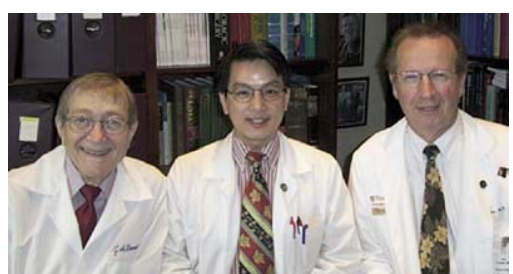

Pierce, Choong, Cooper (left to right)
Extra illustrations are available online. $\mathcal{B}$

From the Division of Cardiothoracic Surgery, Department of Surgery, and the Department of Internal Medicine, ${ }^{\mathrm{b}}$ Washington University School of Medicine, Barnes-Jewish Hospital, St Louis, Mo.

Supported in part by National Institutes of Health grant RO1 HL 62194-04 and the Jacqueline Maritz Lung Center at Barnes-Jewish Hospital, St Louis, Mo.

Received for publication Feb 3, 2005; accepted for publication March 14, 2005.

Address for reprints: Cliff K. Choong, FRACS, University Lecturer and Consultant Surgeon, Department of Cardiothoracic Surgery, Papworth Hospital, Papworth Everard, Cambridge, England, CB3 8RE, United Kingdom (E-mail: cliffchoong@hotmail.com).

J Thorac Cardiovasc Surg 2005;130:922-3

$0022-5223 / \$ 30.00$

Copyright $\odot 2005$ by The American Association for Thoracic Surgery

doi:10.1016/j.jtcvs.2005.03.046

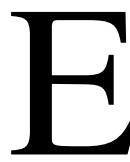

xplanted emphysematous lungs are useful for physiologic and radiologic studies. ${ }^{1,2}$ For accurate ex vivo studies, the lungs need to be carefully prepared, ensuring that they are free of air leakage. We describe an inexpensive and simple technique of lung preparation for ex vivo study.

\section{Technique}

A freshly explanted emphysematous right lung from a recipient undergoing lung transplantation was obtained for ex vivo study (Figure E1). Patient consent was obtained. The equipment used for lung preparation is shown in Figure 1. Secretions within the airways were cleared with a flexible suction tubing. A polytetrafluoroethylene (PTFE) graft was chosen according to the diameter of the bronchial stump, so that it could telescope within the bronchial stump. A straight tubing connector was chosen, where one end of it would fit snugly within the PTFE graft (Figure E2). If the external diameter of the connector was significantly smaller than the internal diameter of the PTFE graft, adhesive tape could be applied circumferentially on the connector until the diameter increased sufficiently to provide a tight fit within the PTFE graft. The other end of the PTFE graft was then telescoped within the bronchial stump and anastomosed with a continuous 4-0 Prolene (Ethicon, Inc, Somerville, NJ) suture (Figure 2, A). A thin layer of glue (Perfect Glue 2; Liquid Nails, Cleveland, Ohio) was then applied over the entire surface of the PTFE graft and the anastomosis and allowed to dry for at least 2 minutes. A Y-connector was then set up with attachments to an Ambu bag (Ambu Inc, Glen Burnie, Md), a pressure gauge monitor, and the lung (Figure E3). The lung was gently inflated by the Ambu bag to no more than 5 $\mathrm{cm} \mathrm{H}_{2} \mathrm{O}$. Air leaks were searched for vigilantly with several methods. An area of air leakage that produced an audible hissing sound was often useful as a guide to the location, which could then be found visually. The area of air leakage was then confirmed by gently occluding over it with the tip of a finger, which would eliminate the sound. If the location of air leak could not be found, normal saline solution was squirted gently over the surface of the lung with a syringe, to spot air bubbles leaking out of the lung surface. The identified areas were then dried with a gauze, sealed by applying a thin layer of glue, and patched over with a piece of latex (Figure 2, $B$ ). The latex patches were made from cuttings from a latex medical glove. In general, the glue and patch would cover the area of leakage and the adjacent 3 to $5 \mathrm{~mm}$ of lung surface, so as to provide a good seal around the leak. Freedom from air leakage was confirmed when saline solution squirted over the entire surface did not reveal any air bubbling while the lung was being inflated to $5 \mathrm{~cm} \mathrm{H}_{2} \mathrm{O}$. The lack of air leakage was further 


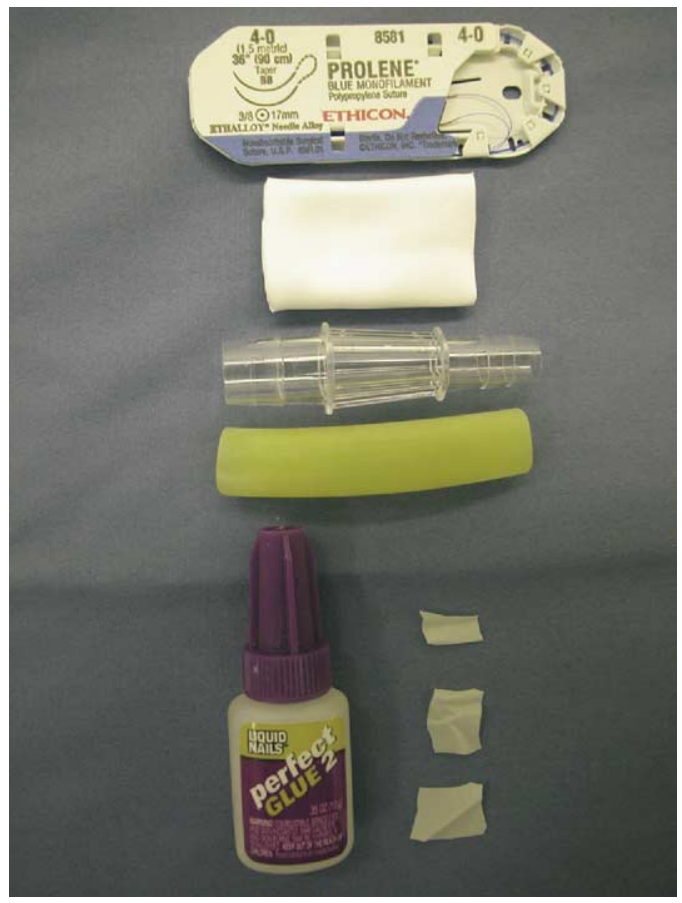

Figure 1. Equipment used in lung preparation. From top to bottom: 4-0 Prolene suture (Ethicon, Inc, Somerville, NJ), PTFE graft (W. L. Gore \& Associates, Inc, Flagstaff, Ariz), straight connector, gumrubber tubing (Cole-Parmer, Vernon Hills, III), Perfect Glue 2 (Liquid Nails, Cleveland, Ohio), latex patches cut from powderfree latex medical examination glove (PSS/World Medical, Inc, Jacksonville, Fla).

confirmed by the ability of the prepared lung to hold a pressure of at least $2 \mathrm{~cm} \mathrm{H}_{2} \mathrm{O}$ for at least 10 seconds when the outflow of the air was occluded after inflation (Figure E4).

The recipient had previous right-sided multiple rib fractures. During explantation, dense adhesions were found between the lung and areas of healed rib fractures. The adhesions were divided. During lung preparation, multiple areas of air leakage were found, particularly around the hilum and on the anterolateral surfaces, where the adhesions were divided. These were sealed with the glue-latex patch technique as described (Figures E5 and E6). Figure 2, C, shows the prepared right lung, which remained distended despite the bronchus being opened to air to allow for deflation. This is in marked contrast to the initial explanted specimen (Figure E1), demonstrating that the lung was completely free of air leakage and the large amount of residual trapped gas within the lung had caused the emphysematous lung to remain distended.

\section{Discussion}

Thirty explanted lungs have been prepared with this technique, allowing successful ex vivo studies. ${ }^{2-5}$ The glue is inexpensive, approximately $\$ 4$ per bottle, in contrast to expensive surgical sealants. It can easily be purchased at most home improvement stores. The latex glove is also inexpensive and has the advantages of being flexible and stretchable, as well as easily allowing for
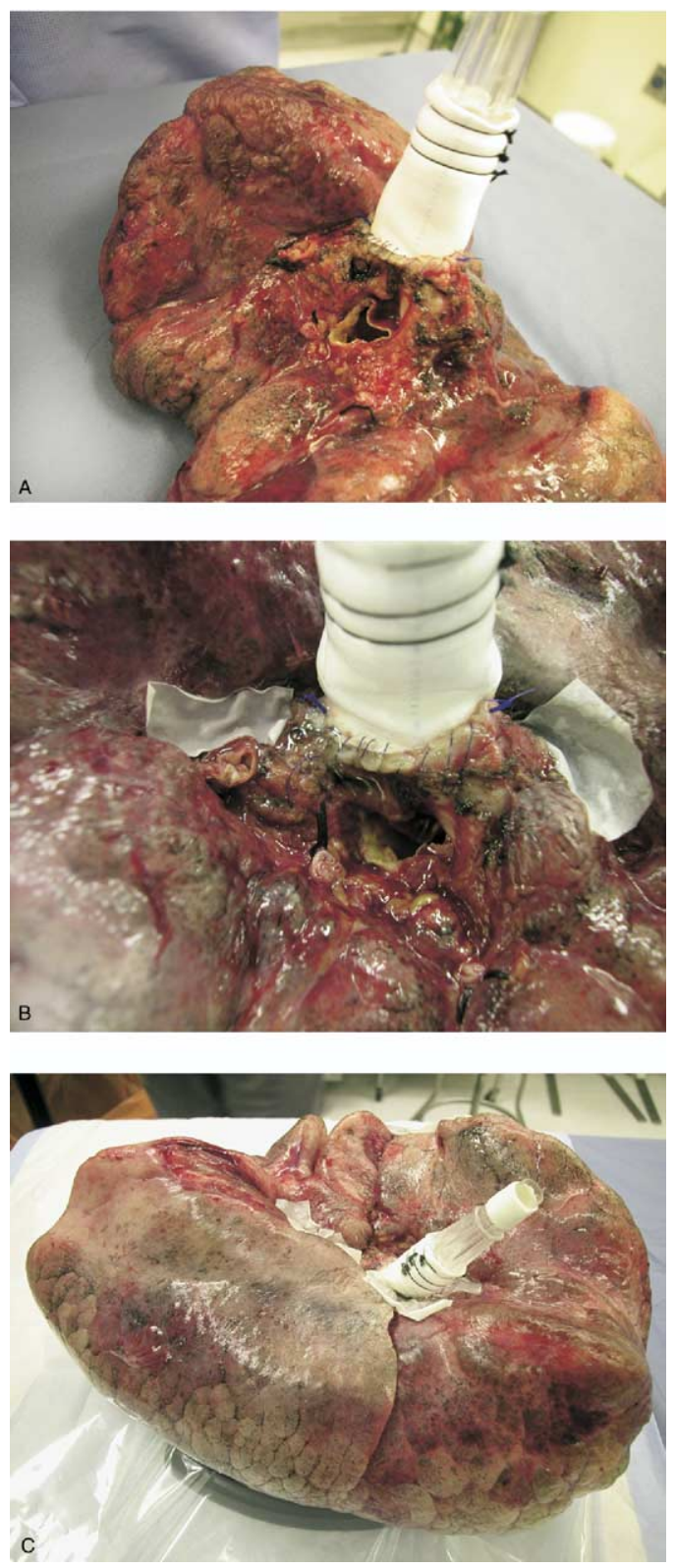

Figure 2. A, PTFE graft was telescoped within bronchial stump and anastomosed with continuous 4-0 Prolene suture. B, Areas of air leakage were sealed by applying thin layer of glue and patched over with piece of latex. C, End result of prepared right lung with bronchus opened to air to allow deflation. Lung is free of air leakage and shows persistent distention from large amount of residual gas trapped within emphysematous lung.

appropriate shape and size of patches to be tailored. The sutures and PTFE grafts used were expired stocks provided to us free of charge from the operating theater and by companies. In conclusion, this is an inexpensive, simple, and reproducible technique of lung preparation for ex vivo studies. 


\section{References}

1. Lausberg HF, Chino K, Patterson GA, Meyers BF, Toeniskoetter PD, Cooper JD. Bronchial fenestration improves expiratory flow in emphysematous human lungs. Ann Thorac Surg. 2003;75:393-8.

2. Choong CK, Wong J, Leawoods JC, Bentley J, Chino K, Conradi MS, et al. Comparison of computed tomographic (CT) and ${ }^{3} \mathrm{He}$ magnetic resonance images $\left({ }^{3} \mathrm{He} \mathrm{MRI}\right)$ of human lungs with emphysema. Am $J$ Respir Crit Care Med. 2004;169:S880.

3. Choong CK, Leawoods JC, Bentley J, Wong J, Chino K, Conradi MS, et al. Measurements of emphysema in human lungs: hyperpolarized ${ }^{3} \mathrm{He}$ diffusion compared to histology. Am J Respir Crit Care Med. 2004;169:S881.

4. Leawoods JC, Choong CK, Yablonskiy DA, Wong J, Pierce JA, Chino $\mathrm{K}$, et al. Characterization of the extent of emphysema in human lungs via ${ }^{3}$ He MRI. FASEB J. 2004;18:A117.

5. Leawoods JC, Yablonskiy DA, Choong CK, Wong J, Chino K, Pierce JA, et al. Short- and long-range diffusivities of ${ }^{3} \mathrm{He}$ in healthy and emphysematous, excised human lungs. In: Proceedings of the 12th International Society for Magnetic Resonance in Medicine. 2004. p. 1683. 


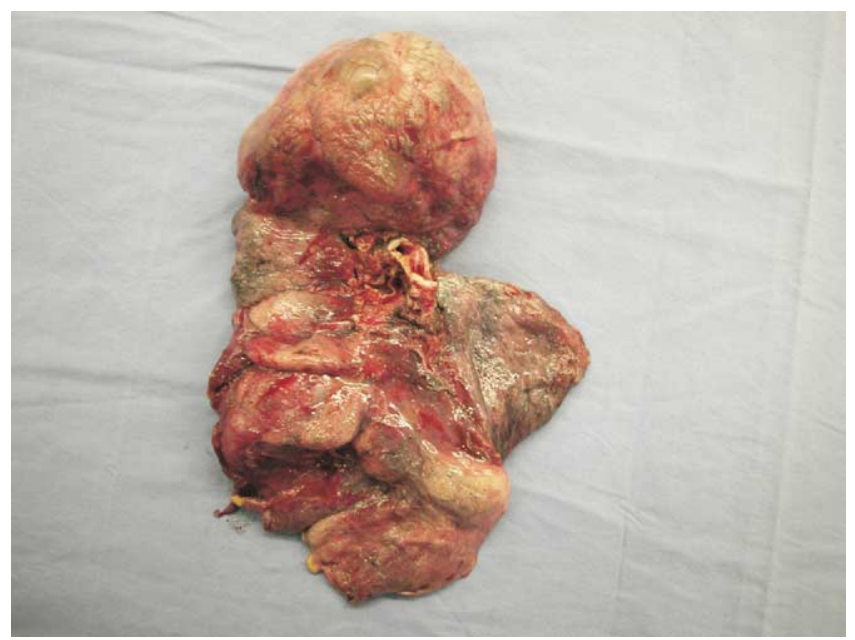

Figure E1. Freshly explanted emphysematous right lung was obtained for ex vivo study from recipient who underwent lung transplantation.

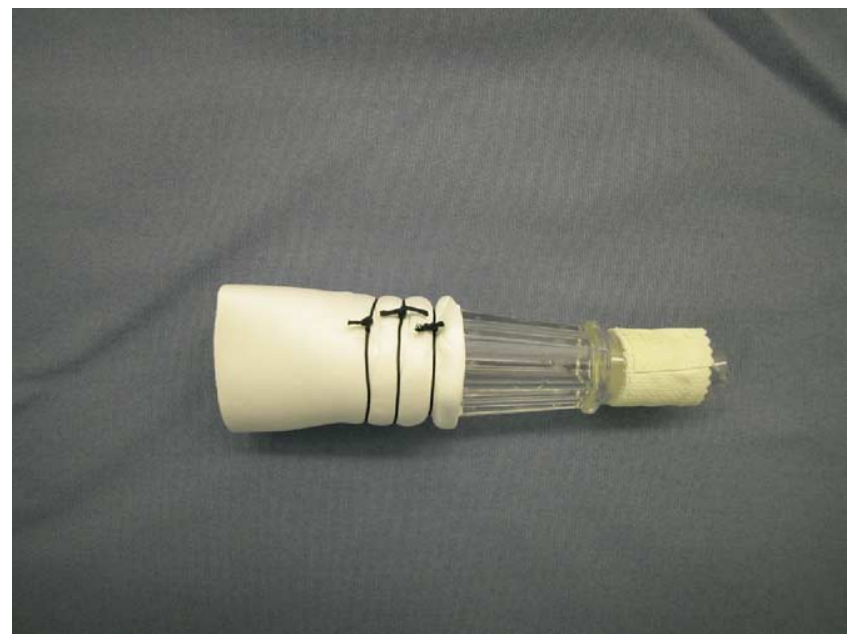

Figure E2. Straight connector with end fitting snugly within PTFE graft. Connection was further secured with three separate size 0 silk ligatures (Ethicon, Inc, Somerville, NJ). 


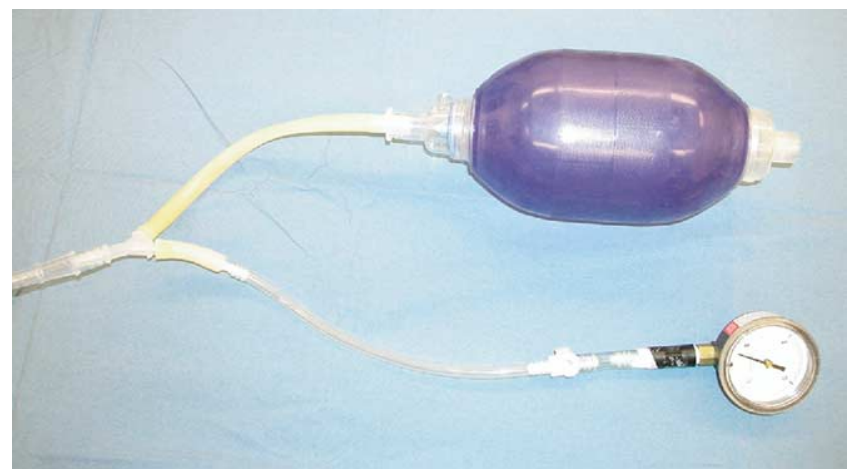

Figure E3. Y-connector with attachments to Ambu bag, pressure gauge monitor, and lung by rubber hose attached to straight connector-PTFE-lung unit. This is to allow monitoring of lung inflation pressure to ensure that it does not exceed $5 \mathrm{~cm} \mathrm{H}_{2} \mathrm{O}$ pressure, to avoid excessive pressure that may cause iatrogenic air leakage from barotrauma.

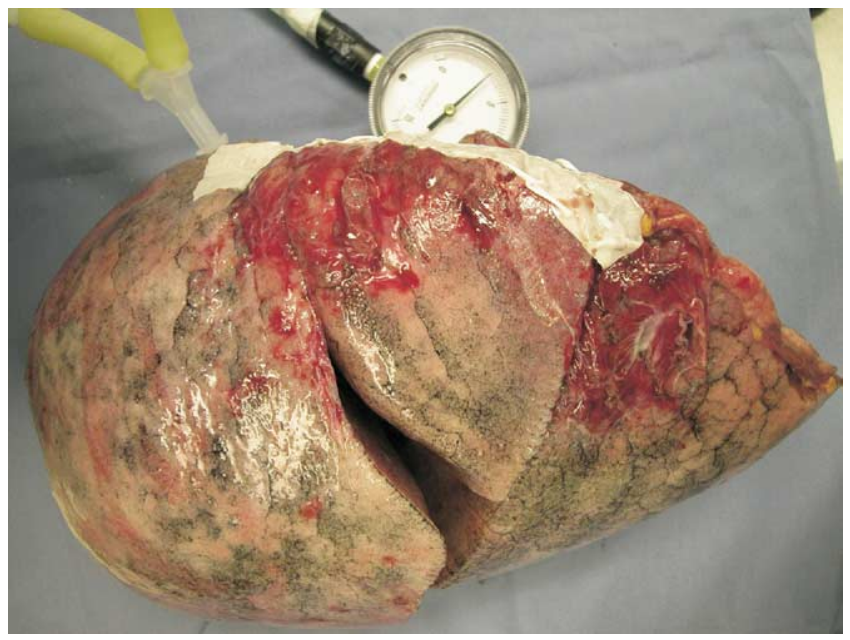

Figure E4. Lack of air leakage was further confirmed by ability of prepared lung to hold pressure of at least $2 \mathrm{~cm}$ $\mathrm{H}_{2} \mathrm{O}$ for at least 10 seconds when outflow of air was occluded after inflation. 


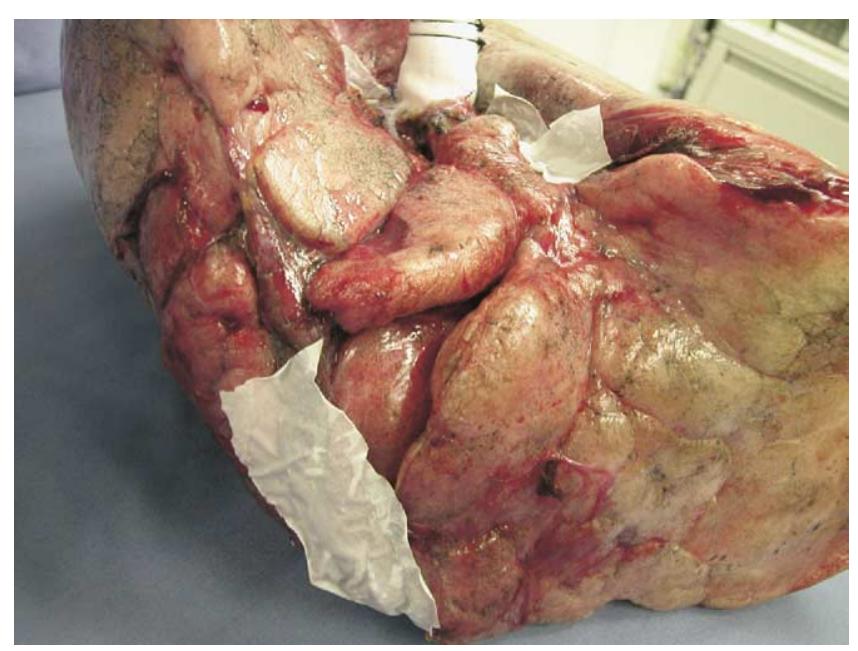

Figure E5. Multiple areas of air leakage on hilar and anterolateral lung surfaces were sealed with glue-latex patch technique.

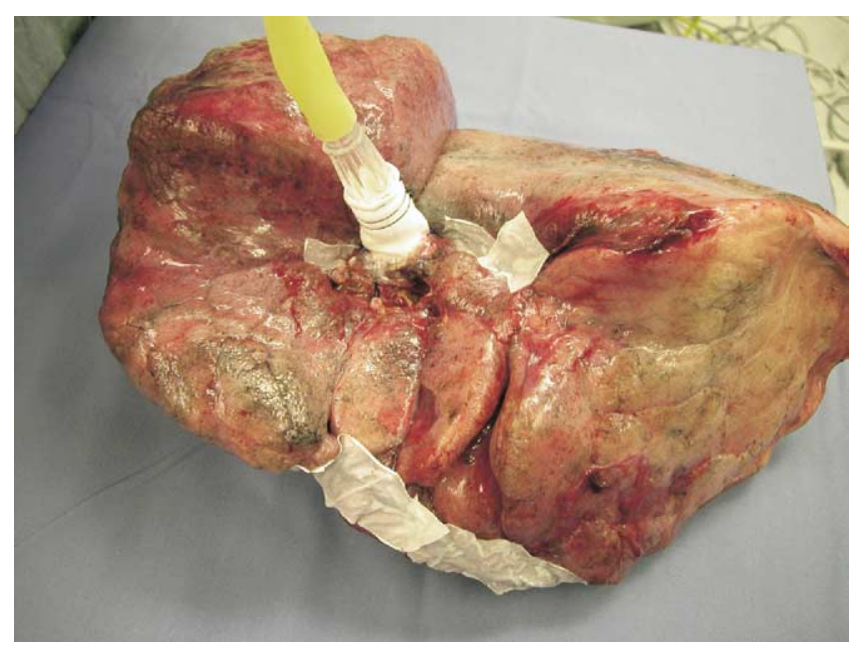

Figure E6. Multiple areas of air leakage on hilar and anterolateral lung surfaces were sealed with glue-latex patch technique. 